\title{
The Vernacular Landscape of Assisted Living
}

\author{
Erin G. Roth ${ }^{\mathrm{a}}$ and J. Kevin Eckerta ${ }^{\mathrm{a}, \mathrm{b}}$ \\ Erin G. Roth: eroth@umbc.edu; J. Kevin Eckert: Eckert@umbc.edu \\ ${ }^{a}$ Center for Aging Studies, University of Maryland, Baltimore County, 1000 Hilltop Circle, Public \\ Policy 252, Baltimore, Maryland 21250, United States \\ ${ }^{b}$ Department of Sociology and Anthropology, University of Maryland, Baltimore County, 1000 \\ Hilltop Circle, Public Policy 252, Baltimore, Maryland 21250, United States
}

\begin{abstract}
This article is an exploration into the vernacular landscape of Assisted Living (AL), a conceptual idea borrowed from cultural geographer J.B. Jackson, which distinguishes formalized, planned space from those spaces which are unintended and often created spontaneously--vernacular. Based upon three large-scale, multi-year ethnographic studies in Maryland, we consider some of the ways people who live in AL relate to and respond to the built environment, at times subverting the intended purpose of design to make it their own. The conflict that often ensues over both planned and vernacular public and private space, we propose is ultimately the product of living within an environment that is both someone's home as well as a place of business, whose job it is to keep people safe. Within this physical context of vernacular private and public spaces, this article enriches understandings about the way autonomy and privacy expresses itself.
\end{abstract}

\section{Keywords}

assisted living; built environment; autonomy; privacy; ethnography; public; sociability; place; vernacular; agency

Cultural geographer J.B. Jackson (1984) coined the phrase "vernacular landscape" as a way to distinguish it from the predominant landscape that is planned, built, commodified, and regulated. In contrast, a vernacular landscape is one that is shaped by the people who live and work within it. He writes, "vernacular landscape is identified with local custom, pragmatic adaption to circumstances, and unpredictable mobility" (1984:xii). One of Jackson's great contributions was his emphasis on the effect human activity has upon the landscape, looking beyond formal architecture and the political forces that maintain it. He was a proponent of studying the commonplace aspects of the contemporary landscape, "spaces of a humbler, less permanent, less conspicuous sort" (xi).

This article suggests viewing assisted living (AL) as a vernacular landscape. We directly consider how residents within AL improvise by modifying the space so that it works for them. We seek to understand the forces that contribute to or detract from a sense of ownership, comfort, and feelings of being "at home." Viewing AL as a vernacular, physical

\footnotetext{
(C) 2011 Elsevier Inc. All rights reserved.
}

Corresponding author. Erin Roth, eroth@umbc.edu, 011-410-455-8732 work, 011-410-455-5931 fax.

Publisher's Disclaimer: This is a PDF file of an unedited manuscript that has been accepted for publication. As a service to our customers we are providing this early version of the manuscript. The manuscript will undergo copyediting, typesetting, and review of the resulting proof before it is published in its final citable form. Please note that during the production process errors may be discovered which could affect the content, and all legal disclaimers that apply to the journal pertain. 
landscape is one way to understand how people use and experience the spaces they occupy in unintended or unexpected ways. Drawing upon hundreds of ethnographic interviews and fieldnotes, we explore some of the ways people shape and are shaped by the physical space they inhabit.

\section{The Landscape of AL}

Assisted living (AL) developed over 25 years ago as a way to address some of the more dehumanizing aspects of nursing home carei (Kane, et al., 2003). The concept emphasizes a home-like environment that fosters respect for an individual's sense of autonomy, privacy, and freedom of choice (Carder, 2002). In contrast to the typical nursing home, most ALs offer private rooms with a bathroom, a kitchenette with microwave, and locks on the doors, all in a hotel-like setting. A choice of entrees is offered and served restaurant-styleii. Handrails are discreetly disguised as chair rail molding and the walls have been papered and windows hung with matching drapery. While the physical plants of ALs vary greatly, from purpose-built, architect-designed buildings to converted cinder-block walled nursing homes built in the 1970s to split-level homes located in the midst of single-family neighborhoods, they all share the desire to be less medical and institutional in appearance and operation than conventional nursing homes.

$\mathrm{AL}$, as a relative newcomer to long-term care, provides an option that older adults unanimously prefer over a nursing home (Kane \& Kane, 2001). Although definitions of what constitutes an AL and the regulations that govern them vary by state, most are guided by a common set of social model "values" in contrast to a more medical model found in most nursing homes (Carder, 2002; Mollica, 2006).

As AL has matured, it has in some ways become susceptible to some of the same problems it sought to ameliorate. The increased reach of regulation, threat of litigation and public censure, as well as the rising cost of doing business necessarily constrains AL's social model values (Ball, et al., 2004). In particular, because people are "aging in place" and therefore older and more frail (Golant, 2008), AL is no longer the place it was designed to be. As so many administrators have told us, assisted living has become the new nursing home.

AL today is a well-known entity--firmly entrenched in the American senior housing landscape, the American psyche and our everyday lexicon (Golant \& Hyde, 2008). It is the setting for novels and motion picturesiii, commonly evoked in everyday conversations all over the country. It has become a place "entwined with personal memory," (Lippard, 1998). What began as "space," that is, a concept with bricks and mortar has become a "place," bestowed with cultural meaning and life's experiences (Tuan, 1977). Assisted living is a clearly defined entity - a place bounded by discrete borders, governed by regulations and rules, serving a defined group of people, in a precise moment of time. These specifications, however, in no way suggest that AL is static and unchanging. The reality is that AL is continually in flux, adapting to changes in ownership, alterations in the physical plant, evolving policies, adjustments in the services offered and fees charged. Our research has shown that services may be cut with little warning, well-liked employees may leave, and residents eventually move or die (Eckert, Carder, Morgan, Frankowski, \& Roth, 2009;

\footnotetext{
iSkilled nursing facilities have and are undergoing a reinvention as leaders in this area are advocating "culture change" that would introduce many of the AL philosophies to nursing homes (cf. Weiner \& Ronch, 2003; Rahman \& Schnelle, 2008). But this is still relatively slow to develop, impeded by nursing homes' long, institutional history and heavily regulated nature (Kane, et al., 2003). $\mathrm{ii}^{\mathrm{A}}$ restaurant-style dining experience may seem an apparent contradiction to AL's value upon creating a "home-like" environment. However, the hospitality of a restaurant/hotel is consistent with the consumer-driven philosophy of AL (Carder \& Hernandez, 2004). iii See for example the critically acclaimed mock documentary called "Assisted Living" (2006), a mystery novel by the same title, written by Sheila Ortiz Taylor (2007), and Breaking out of Bedlam: A Novel (2010) by Leslie Larson set in an assisted living facility.
} 
Morgan, et al., forthcoming). These factors impact the lived experience of residents in both the short and long term. In this paper we explore the convergence of people and place, recognizing the effect $\mathrm{AL}$ as a physical, conceptual, and phenomelogical place has upon the people within it and the effect residents have upon the place. It is this convergence of people and place, and what happens within that convergence that we refer to as the vernacular landscape.

\section{Sensitizing Theoretical Concepts and Framework}

The person-environment fit and congruence models have informed much of the research in the area of housing and care for older adults (c.f. Kahana, 1980; Lawton 1980; Lawton \& Nahemow, 1973). Lawton's work has been pivotal to the development of environmental gerontology as a subfield of gerontology (Wahl \& Weisman, 2003). His work continues to shape today's long-term care models; he proposed the creation of multi-level care settings where environment would match individual's competency levels (Calkins, 2003). Calkins writes in her retrospective on Lawton's contributions to long-term care settings: "He argued early and persuasively for the development of what is now called assisted living" (69). Lawton's ideas remain relevant today and have been developed further by Lawton himself as well as others (cf. Lawton, 1998; Parmelee \& Lawton, 1990; Rubinstein \& de Medeiros, 2003) and continue to be refined (cf. Wahl \& Weisman, 2003). By thinking of AL as vernacular space, we suggest a new and complementary way of seeing how environment and person interact and impact each other.

Setha Low and Denise Lawrence-Zuniga, in their book The Anthropology of Space and Place (2003), synthesized extant anthropological literature around six thematic categories. Their work contemporizes Jackson's work and the Person-Environment fit model by exploring the fluid and political nature that space and people occupy. Five of the six thematic categories they describe are relevant to the topic of AL as a vernacular placeembodied, inscribed, gendered, contested spaces, and spatial tactics. (The sixth category, transnational spaces, describes the movement of people in a global economy and the dissolution of borders, and is not included in this discussion.)

Embodied space refers to the material way the body experiences space. Spatial orientation and bodily movement contribute to developing a sense of place. Inscribed spaces are those places that through experiences over time become imbued with memories. In turn, the places are inscribed or marked by the people who have inhabited them. Gendered spaces are those places that embody culturally-ascribed gendered meanings. Contested spaces address the more political aspects of space and how it is controlled by those with power and experienced by those without. Spatial tactics speak to how space itself can be used as a social control device. Low and Lawrence-Zuniga draw upon Michel Foucault's argument that architecture is essentially a political technology employed to organize and enclose individuals within a space, intentionally creating a "docile body" (Foucault, 1975:198). How and why these tactics get used exposes power imbalances, an insight resonant with our findings and evident within our ethnographic data. Low and Lawrence-Zuniga's categories naturally overlap, but provide a way of further describing the ethnographic material we present.

For the purposes of this article, we have assembled the spaces within AL into two overarching groupings-Public Space and Private Space. The intended use of public and private spaces in AL on the surface appears straightforward: public spaces include lobbies, lounges, dining room, hallways; private spaces include the resident's individual room. How these spaces are used and conceived of can vary greatly. Public spaces are often tightly controlled by staff who put restrictions on who uses them and what happens there. And because staff members need access to rooms to provide oversight and assistance, there are 
limits on how much privacy residents' rooms can afford. Private rooms may be entered despite a locked door and staff are often familiar with the items residents' keep in their drawers, sometimes helping themselves to a piece of candy or borrowing a Depend because the resident next door ran out.

The unintended or vernacular uses of these public and private spaces are the main focus of our discussion. In this examination, we echo Graham Rowles' early work, Prisoners of Space? (1978), by observing the creative and adaptive strategies older people employ and by viewing individual agency through the subtle ways residents live within their space. At times embodied, inscribed, contested, and/or gendered, how public and private spaces are ultimately used (or not used) can offer insights into how life in AL is experienced, on the ground.

\section{Methodology and analysis}

Data are drawn from three multi-year ethnographic studies of 17 AL settings in Maryland and include interview transcripts, recorded fieldnotes from observation and participation, and informal conversations. The three studies employed qualitative research designs that involved extended fieldwork in AL settings that varied in size from small board and care homes to large purpose-built ALs. For convenience and logistical reasons, all settings were located within Maryland, but included samples from urban, rural, and suburban locales. These studies have resulted in a variety of publications which can be consulted for more detail (Eckert, et al., 2009; Morgan, 2009; Morgan, et al., forthcoming).

Over the course of eight years, ethnographers spent six to ten months at each of the 17 settings, with an average of 320 hours of fieldwork at each site. In-depth ethnographic interviews were completed with $236 \mathrm{AL}$ residents, 132 family members, and 167 staff members. Ethnographers' fieldnotes, in which experiences and observations from the field were recorded after each field visit, totaled 370. Interviews were transcribed verbatim and checked for accuracy, and systematically coded using a set of inductively derived codes (Taylor \& Bogdan, 1984; Agar, 1980; Miles \& Huberman, 1994; Crabtree \& Miller, 1992).

Interview guides for each of the three studies varied according to the specific study's key scientific aims. However, consistent throughout each study was a commitment to the use of ethnographic interviewing and participant-observation to understand residents' meanings, perceptions and attitudes concerning life in the AL. Ethnographic interviewing allowed the interviewer to explore an interviewee's perspective, definitions, and experiences; it also provided an opportunity to use responses as new starting points for additional lines of inquiry (over those originally supplied by the interviewer). Questions in the open-ended interview guides included: "How did you come to live here?" and "What is life like here?" In addition to getting the transition story for each resident (i.e. how they came to live there), we asked questions about social life, informal health assessment of self and others, comparisons with previous living situations, etc. Interviews with staff and family members were similar in that they were open-ended and focused on staff's personal experiences as they related to their job within the AL setting or family's relationship with their relative and the AL itself.

Fieldnotes and interview transcripts were coded in teams and entered into Atlas.ti (Muhr, 2008), a qualitative database software package developed for facilitating qualitative analysis. Analysis involved identifying common themes and patterns throughout the data, utilizing Atlas.ti to run a variety of queries related to code occurrences and co-occurrences, as well as a series of word searches. Data, including ethnographers' impressions, were discussed at bi-weekly team meetings. To ensure coding integrity, rotating two-person teams coded the same documents individually and then met to reconcile any differences. Rotating 
within teams ensured inter coder reliability. When discrepancies emerged in the assignment of codes to text that could not be resolved within the coding team, they were brought to the larger group for discussion and resolution.

Atlas.ti was used to search for codes such as "room" and "public spaces," as related to how residents talked about their rooms and public spaces such as the dining room, lobby, and hallways. Narrative data obtained through the search were analyzed for themes and patterns. The lead author of this paper is one of the ethnographers, allowing her to draw upon direct experiences in the field.

Our research was approved by the university's Internal Review Board. Verbal informed consent was obtained from those we interviewed. AL administrators assisted us in informing residents, family members, and staff through a variety of written, in-person means. In acknowledgement of the AL's participation in the study, each setting was given a small stipend to use for the benefit of the residents. Anyone who did not wish to participate was given the opportunity to decline. All names of individuals and AL settings have been changed to protect the privacy and confidentiality of those interviewed.

\section{Findings}

While giving a tour to a prospective resident and her son, the marketing director said, as they passed by the beautifully redecorated lobby and dining area, "We think of your room as your bedroom and the rest of the building is yours to use as you would your house." Implicit in these words is the idea that the resident will be free to use the space within the building as she pleases, with the understanding that she has control over her own bedroom and in turn must respect the privacy of others within their own rooms. But what our data reveal is that public, social space is most often controlled and restricted by staff, and a resident's individual, private room is not as private as one might expect. The following sections illustrate the ways these expectations are in many ways misleading. We also demonstrate the subtle ways AL residents demonstrate self-determination in how they relate to and adapt the built environment to meet their own needs.

\section{Public Space: Planned}

First impressions matter a great deal to those who are marketing $\mathrm{AL}$ and so the appearance of the lobby, a setting's "front stage" (Goffman, 1959), can often be the site of conflict (Lawton, 1980:100). As a way to manage first impressions, the Chesapeake, a large and upscale, purpose built AL, had the front lobby chairs removed to keep residents from gathering in the lobby. A poignant example of a spatial tactic, the administrators were concerned that a visitor's first view of the AL would be of residents sleeping in the lobby chairs. The receptionist seated behind a hotel-like concierge desk referred to the people who gathered in the lobby as "my little regulars." "It is not the best image for [the Chesapeake]," she said. "In fact," she continued, "a lot of the residents don't like that image either." Mrs. Drake, a Chesapeake resident who regularly paced the halls was asked why she keeps moving. "I walk around so I don't end up falling asleep, like that," she responded, pointing toward a resident who was in her characteristic pose on one of the wing-backed chairs in the lobby, head leaning back, mouth wide open, fast asleep. These chairs were eventually removed.

Laurel Ridge, another large, purpose-built AL but less upscale, was also concerned with first appearances when it decided to remove all chairs from the front area. Residents would become "territorial" as a receptionist described it, objecting to other residents sitting in their seats. One residents' niece opinioned: "I was kind of glad when they put them [the residents] back there because you walk in, you know, your first impression of a home, they'd be sitting 
there arguing." Aside from the receptionist's desk and a birdcage, the lobby area was empty. Arriving visitors, asked to wait, would look around awkwardly for some place to sit and would eventually give up and find a wall to lean against.

Smell is a particularly powerful indicator of quality within long-term care settings for visitors, family, and prospective residents. AL is often distinguished from a nursing home by the absence of odor, as indicated by a number of people we interviewed. A resident at Laurel Ridge noted this absence as she sat in the seat of her walker in the chair-less lobby: "Some people think this is a nursing home. It's not a nursing home. It doesn't smell like one." The receptionist agreed: "You're right. It doesn't smell like one."

Great care is taken to remove any bad odors, even if that means removing people from an area. A staff member at Wetherby Place, a privately-owned, upscale AL, noted the smell of urine, indicating that those residents known to be incontinent are strategically moved to rooms at the ends of corridors, so that visitors and other residents are not subject to the smell. Other places mask odors with Lysol sprays or baskets of potpourri in the lobby. Some ALs will bake cookies from ready-made dough, a scheduled activity for residents that has the added benefit of creating pleasant smells that permeate the building.

Another example of contested spaces comes from Arcadia Springs, a medium-sized purpose-built AL. One of the setting's two treasured sunrooms was walled off and converted into the director's office. Mrs. Coffman's daughter and son-in-law, Alice and Don, lamented the loss of the sunroom, a space their mother used often since it was near her room.

Referring here to the sunroom, Don said, “...that really sold us on the place--was the openness of it, you know, when you walk down the halls, and at the end of each floor was a big open area... a sun room." "And Mom sat in there a lot. She would sit out there with her coffee and read," Alice added. When asked if the residents or families had been consulted or informed ahead of time, the daughter responded, "Well, I'm sure, I mean, that's their prerogative. They aren't going to ask us." They referred to the loss of the sunroom as "a real shame."

Alice: It was a shame.

Don: Because she wasn't the only one that used it. A lot of other people would go down and read. That one man was reading all the time.

Alice: And some of the family of the residents when they come in--

Don: It was giving you a place to sit.

Alice: Their birthday or something for their parents. They would go down there and have their cake, and you know, they'd bring a cake in for their mother or their father.

The builder's original plan located the director's office on the second floor, overlooking the front of the building but because it was so far from the entrance, the director's predecessor had moved the office to the first room off of the main lobby. The room was designed as a single resident's room. The current director moved the director's office again, this time to the sunroom located at the far wing of the first floor. The vacated office reverted back to a resident room.

The dining room is an important social space that often becomes contested. It is the one place where residents are expected to come together, three times each day. There they negotiate walkers, seating arrangements, annoying or bothersome eating behaviors, or cognitive or hearing impairments that make communication difficult. There can be conflict 
with staff members who are perhaps disgruntled with their work or short on patience with the residents that day.

Anything from medication distribution to finger pricks can take place at a resident's table. Some settings have rules forbidding med techs to work within the dining room as a way to adhere to the social model of AL. But, for convenience, many med techs will station themselves at the entrance of the dining room to distribute medicine to those entering or leaving. While HIPAA (Health Insurance Portability and Accountability Act) prevents the sharing of medical information and has changed some practices in AL, preserving privacy is not always practical or feasible.

An ethnographer recorded these notes from an observation she made while at Middlebury Manor during lunch one day. Middlebury Manor, a second-generation, family-owned AL, serves a mostly middle/working class clientele. This observed interaction demonstrates why privacy is so difficult to maintain in a place like an AL dining room.

At one point, Mr. Mueller pushed his wheelchair away from the table and called to someone that he was ready. Jada, who was sitting in a corner drinking a soda, told him she could take him as soon as the other CNA returned from her lunch break. It was not too much longer that Mr. Mueller said again he was ready. Jada told him he needed to wait. This began to anger him. He finally said, "Do you want me to pee my pants?! I said I need to go!" Jada responded from across the room, "Well you didn't tell me that you needed to go to the bathroom. There's one right here." "I have to save my pee in a cup, dammit. I can't go here. Now I've shared all my personal business with all these people!" he said. He was really angry and I think Jada misunderstood him when he then said, "Now I've had to get so damn nasty." At least that's what I heard. But she must have heard him say, "Don't get so damn nasty!" Because she then responded, "I'm not the one getting so damn nasty. You are." As she said this, she was bending over, getting his foot rests in place before she wheeled him away. He said, as he was being wheeled out of the room, "I'm not 8 years old. And I don't appreciate sharing all my personal business with these people."

There was no villain in this situation. Both Jada and Mr. Mueller were caught by the unfortunate spatial realities of having to live a private life in a public place.

Public, shared space in AL, as demonstrated in these examples, is often controlled by staff and administration. Residents tend to play a supporting and often passive role. Favorite sitting areas may be co-opted by administrators and lobbies may be made unusable. It may have been disingenuous to portray these public spaces as "yours to use as you would your house," but the marketing director who gave the tour to the prospective resident genuinely believed what she was saying. Exemplified through these examples is what Low and Lawrence-Zuniga refer to as contested spaces that lead those in power to at times employ spatial tactics to control who and how a given space is used. These tactics, Low and Lawrence-Zuniga argue, reveal deeply held cultural values, which in this context may be avoidance of aging and decline. By removing certain residents from the lobby, visitors, other residents, and potential customers are not immediately faced with the discomforting images of illness and disability.

\section{Public Space: Vernacular}

In the following ethnographic description, residents play a much more active role in creating and defining a social space they called "The Forum." We assert that The Forum had become a vernacular social space, created, as they shared with us, in response to the lack of warmth and welcome they felt in the formal sitting areas. This space became embodied, gendered, 
and inscribed, serving as a crucial social gathering space for a group of women at Murray Ridge, a working class AL located in a building originally built as a nursing home.

The Forum was informally established when a group of women residents decided one day to pull out chairs from their rooms into the hallway that faces the back of the building. Because of its location next to the elevator, the shower room, and the cleaning supplies storage room, there was always a steady stream of traffic of residents and staff. The staff and administration respected this space and would leave the chairs in place when the group was not gathered.

One afternoon, the ethnographer sat with the group while the recorder was on. The women, who knew they were being recorded, explained to her how The Forum developed and what it means to them.

Mrs. Robles: You know, we started out here with two chairs. And now we have seven. We all get together every afternoon sometime after 2:00. And it is really nice.

Mrs. Kemp: I'm getting so I love it here. I don't want to go anyplace. My daughter comes to see me. My grandson comes to see me. They bring me fruit and cookies. And it is too much and we just pass it around. I like it here.

Mrs. Robles said of Murray Ridge and the people there, "I feel loved for the first time in my life."

When asked why they do not sit in the lobby, they respond that the lobby is for prospective residents and families or for business; they did not think they would be allowed to sit there. Mrs. Robles said they have a "lounge" but it does not appeal to her. The ethnographer writes in her fieldnotes:

Mrs. Kemp comments that "we have a gang here" and implies that they know everything. I tell them that from now on I am coming directly to them for the news.

Mrs. Robles calls Mrs. Kemp "Breezie" and I try to get someone to explain that. But everyone is laughing so hard they can't talk. And Mrs. Kemp actually likes the nickname. She tells me she likes everyone here. "We have a good time."

We talk about how people gripe about things. And how sometimes it is good to ask for what you need. Mrs. Kemp says she doesn't like to say bad things about anyone or anything, so she usually lets it go by. Mrs. Robles pipes up that there are a few who gripe enough for the rest of them.

As a social space, The Forum was a success. By understanding the social interaction that took place there, we may begin to understand the social and emotional support that this group of chairs had become for those women.

Unfortunately, the fire marshals during a routine inspection put an end to the gathering place. Around the same time Mrs. Robles, a key member of The Forum, ran out of money and was forced to take a room in a nearby nursing home that accepted Medicaid. Despite the AL administrator's efforts to recreate The Forum elsewhere, it could not be replicated.

Designers and administrators of senior housing ponder ways to create social spaces that emulate the success of The Forum. The director of Piety Home, a privately-run AL located in a converted mansion, noticed with some amusement that no one sits in the beautifully renovated formal parlor. 
I really don't know what it is. [A professional design group specializing in aging] designed it and we all thought it would be great but - no clue. They'll sit on the other side where the mailboxes are, but they don't sit in the Victoria room. And next year I was thinking about putting a little electric fireplace in there, because now I'm curious; why won't they go in? What can I do to make them go in?

Anthropologist and social gerontologist Phil Stafford, in his book Elderburbia, directly addresses what this administrator was struggling to create. Stafford writes, “.... sociability is above all a product not of cultural spaces, but of the 'work' of participants and thus can be constructed in about any environment" (2009:105). These places where people gather become embodied and inscribed with meaning, memory, and life. Stafford notes the failure of those who try to construct social space is in not recognizing that "in sociable settings, elders are producers, not consumers" (127). These social spaces have an ephemeral and fortuitous quality; they are the creation of the people who share in common a desire for social connection and are fortunate to find each other at that point of time. But in a place like $\mathrm{AL}$, where people are likely to move or pass away, social space does not necessarily replicate itself in the same way again.

\section{Private Space: Planned}

Room size, layout and décor vary tremendously between the AL settings we have studied. A good example is the contrast between Wetherby Place, a more upscale purpose-built AL and Murray Ridge, the site of The Forum, whose model rooms are each described here by an ethnographer:

[Murray Ridge's demonstration room] couldn't have been more contrary to the demo room in Wetherby Place. While Wetherby's room was warmly decorated with flowers, a set table and chairs, a bedspread, furniture, a nice lamp, and some (generic) photographs, the [show] room at Murray Ridge contained one hospital bed with a thin, rough blanket, tucked in with hospital-corner-precision. The walls were bare with only the sea-foam green paint; the floors were sterile tile. Save for the overhead light in the bathroom, there were no lamps or ceiling fixtures, and there were certainly no places to sit, except for the extra-springy and firm mattress.

The background of the prospective resident (and ethnographer!) is an important factor in how people experience a place, either drawn to or repelled from a place based upon personal, aesthetic preferences. Where the person has lived before and the amenities they have come to expect will determine what they will tolerate, embrace, and/or accept (Rubinstein \& de Medeiros, 2003). Mr. Leland of St. Brigid's, a small, religious AL serving low-income elders, noted his frustration with the size of his especially small room. "I would never have this small a space for a person to live in. And you can say, well, maybe it's because I always lived in a bigger place, and that's true. But I don't think many of them that live here lived in this small a place.” The room, perhaps six feet by 15 feet, was especially crowded. His recliner sat in the middle of the room, facing the small TV atop a dresser against the short-end of the back wall. He suggested an extra ten feet would give him "enough room to breathe."

The rooms intentionally vary within the purpose-built AL settings and are priced according to size, view, and location. The retrofitted AL's have less control over room size and lay-out because the building was originally designed for a different purpose, such as a nursing home or in some cases mansions built a century ago on large estates.

\section{Private Space: Vernacular}

Selecting a room and making it one's own is for many the first step toward settling in. Mrs. Marshall expresses this in her interview: "I didn't really want to come, but after I came I had 
to get adapted. One thing I like is the room and I liked the scenery here-the reason I took this room. So that in itself helped me to a certain extent." An individual's room is the one space within AL that can be decorated and furnished as one wishes. The rooms become inscribed by the individuals who live there and reflect something of that person. Some choose to use the provided furniture while others select paint color, draperies, and buy new furniture. Some rooms reflect a retired profession, a passion for art, a devotion to family or faith (Rubinstein, 1990). Even in what may be a less than ideal physical and social environment, by investing emotionally in one's room and surrounding oneself with familiar, meaningful objects, it is possible to foster a sense of well-being and comfort. This is what Rowles, Oswald, and Hunter refer to as "a sense of being in place" (2003).

Ms. St. John turned her room into an art studio, which also served as her living space. Her tables were covered with open and closed paint containers, piles of paper, and cardboard stacked all over the room. Her large pieces of artwork were being stored at her church, but she said they were running out of closet space. She housed works along her "studio" walls and behind furniture, including her bed. Another artist resident worked out an agreement with the director, while the census was low, to store hundreds of her paintings in an empty resident room. Another artist kept an easel near her recliner with paper and charcoal pencils within reach. She, too, like Ms. St. John and other artists we have met, commented on the importance of their room's natural light.

Mrs. Harding's room was in essence a shrine to her faith. One of two posters on her door held startling images of spiritual warfare-in addition to the poster of the Vatican Chapel, the second poster depicted a scene right out of Revelations that read: "There's a battle going on in here. Whose side are you on?" Nailed to the wall just beside the door was a little ceramic font to hold holy water. She kept it filled and ritually dipped her finger in as she left the room, crossing herself as she went. Hanging on walls, setting on shelves throughout the small room were crucifixes and depictions of the Virgin Mary. A huge string of rosary beads - made primarily out of what looked like silk flowers, bordered the frame of a depiction of a Catholic saint. Above her bed were three $8 \times 10$-framed photos of her family - one was a 20 or so year old photo of her and her husband. The walls were covered. And she had stacks of files and papers wherever she had room - underneath the little writing desk, behind the recliner, etc. She had begun storing stacks of her unopened mail in the shower which she had stopped using, preferring to wash up at the sink.

Many individuals keep and display those items that mean the most to them--a wall of framed family photos, a cherished cedar chest, a set of model airplanes. For Mr. Jones, the most prized item was his daily Wall Street Journals which he would leave laying about his room. Dedicated to following his stocks, he expressed frustration when his papers would be discarded before he had time to read them. Dr. Luckinbill, inquisitive by nature, took an interest in learning from where each of the primarily African care aides immigrated. He kept an atlas setting on a table opened to the two-page spread of Africa. Whenever a new aide would come in, he would ask them to point out their country on the map. Men's private rooms in particular were often more sparsely furnished and decorated. Dr. Smith, for practical reasons, kept his room clear of excess decoration and furniture. He also recognized how the rooms are in many ways gendered:

I don't have much in my room. Sometimes I walk down the hall, people leave their doors open, and I see stables of furniture. I have a man's room. It's $80 \%$ widows with walkers here. They have big TVs, couches, pillows. My room is Spartan so I can get around.

Living in one room often means there is no separate place to entertain. When someone comes into the room, they come immediately into what most people consider the most 
private part of the home- the bedroom. Not everyone can afford a suite or a large enough room to create both a living space and a bedroom. Very often, there is no place to sit in the room except on the bed or in a vacated wheelchair, which is where we would sometimes sit to conduct an interview. One resident's daughter said,

It's not good to have them go live in their bedroom. I think they need to have a separate area for a sitting room kind of thing, because no matter how many public spaces you have, I don't think that most people want to go use the public spaces. These are people who came out of private homes. They're not - they're socialized but they don't want to always be socializing. So they kind of need, they need some private spaces.

Therefore, we have found that more often than not, residents do not invite each other into their rooms. One spatial tactic for those with one room was to simply not use a bed. One woman slept in her recliner and another slept on her couch, never bothering to move a bed into their rooms so they could entertain in a proper sitting room. And though suites often come with a separate living space, if the suite was shared by two non-related individuals, the common living space was not used for socializing as was intended. Instead, the space became a storage area for items that did not fit into the bedrooms.

For many, one's room is a place of refuge. One resident said she prefers to stay in her room away from "all the hullabaloo." The prevalence of dementia in AL is why some residents without cognitive issues choose to separate themselves. "A lot of them don't have it all upstairs. That's why I stay in my room practically all the time, except playing Bingo - and that's all I come out for," one resident told us. Dr. Smith, told of a time he attended Trivia, a regularly scheduled activity:

[The staff member] had a crowd of people downstairs and she had all these Trivial Pursuit questions, and I knew the answer to all of them. I finally left and she said, "Where are you going?" and I said, "Well, this is like shooting fish in a barrel. How about some hard questions?" You know, [she asked easy questions like] who played opposite Ingrid Bergman in Casablanca or something. I kind of gave up on that. It was just - I couldn't keep my mouth shut and I couldn't resist saying the answer. And everybody else is sitting around half asleep. I went back to my room and watched TV.

This attitude is consistent with the findings of a Norwegian qualitative study on the use of common living spaces in nursing homes; individuals with greater health resources tend to withdraw from common areas, exerting more control over where and with whom they wish to spend time (Hauge \& Heggen, 2008). The decision to withdraw to one's room could be viewed as a spatial tactic on the part of the resident.

The room itself becomes inscribed with memory and embodied by physical experience. For example, the weeks after Mrs. Seaton made the difficult decision to euthanize her cat Rudy, she said she was reminded daily of her loss every time she would open the door to her room and instinctually place her cane in the crack of the door to prevent Rudy from running out. Sitting on the sofa, she would imagine Rudy jumping up on the back of the sofa to look out the window. Another resident felt safe and secure in her room, confident in the bodily knowledge of where things are in her room should she fall. "Yes, [I have fallen] a couple of times - but nothing bad. A lot of times I'm in my room - I twirl around and I fall across the bed."

Private space is often contested and becomes redefined within this context. Initially, residents are often surprised by how freely staff come and go in their rooms (Morgan, 2009). Some AL's do not provide locks for individual rooms for safety reasons; and those that do 
provide locks can override the locks with a master key that nearly every aid and housekeeper carries with them. It is common to knock once and then immediately enter a door, not waiting for an answer. Nightly checks are made on residents and if their room was locked before going to sleep, there is no guarantee that it will remain locked throughout the night, leaving a resident vulnerable to uninvited guests who wander at night.

Residents are aware of the public-nature of their private space and deal with this encroachment in various ways. One resident would place an inconspicuous piece of tape across her door so if she returned and the tape had been disturbed, she would know someone had been in her room. Another resident would nightly shove a chair underneath the handle of her door, which was a source of conflict with her daughter who wanted the night checks and the mother who was unable, in the end, to overrule her daughter's wishes. Mrs. Merrill was surprised to find a confused intruder in her room one night.

Some funny things have happened out of something sad. I was in bed one night and I didn't have the door closed; I hadn't closed it. All of a sudden - (there is one lady here that sounds like she is so mean; she might not be, but she has a voice like that) - here comes this woman rolling herself in my room and she said to me, "Turn the television off." And I said to her, "Pardon me?" because I was in bed. And she says, "Turn that television off." And I said, "Why? Why do you want me to turn the television off?" She said, "Turn the television off." I said, "I think you are in the wrong room, honey. Why don't you wheel back and go to your room. You are in the wrong room." And she looked at me for a little while. I said, "You are. You really are." And finally she backed up and left.

As Mrs. Merrill reflected during her interview, she was perhaps less annoyed and fearful as she was intrigued by the woman's cognitive impairment and even empowered by her ability to talk this gruff woman out of her room.

Restrictions placed upon residents as to what they can keep in their rooms are very common. Most of the $17 \mathrm{AL}$ settings had policies that restrict over-the-counter medication or other potentially harmful products from being kept in one's room. Two ALs would routinely search rooms for such items and confiscate them. Mrs. Jackson, a usually very accommodating individual expressed her frustration:

You don't have anything. If you want an aspirin or Tylenol, you have to go to the nurse. And the doctor has to have it on your record. [Before moving here], if I wanted something, felt that I needed an aspirin, I could give it to myself. But I can't do it here, because I can't do anything. You know, the nurse came and looked in my drawer - my night table drawer and she took everything.

One resident knew of the over-the-counter medicine restriction but kept a bottle of camphophenic in her room anyway. The label had conveniently fallen off the bottle, "so I'm hoping the inspectors don't see that!" she said with a laugh, aware she was breaking a rule.

Over time, residents who spend down their money have in some instances been accommodated by the AL by being offered a smaller or shared room. Though sharing a room is not in keeping with AL's original ideals, it has allowed residents to remain within the AL. Mrs. Messer of the Chesapeake said this of her pending move: "That's what happens when the money runs out [...] For a couple hundred dollars you have to downgrade yourself. I hate the thought of the things I have to leave... windows, I met nice people." With little or no choice in roommates, Mrs. Messer's new room was to come with a roommate who she said had a reputation of "not being too nice." 
Mrs. Tice, a centenarian and several-year resident at the Chesapeake had been through her share of roommates. Though she had obvious challenges with some roommates, she chose to stay positive about the next, grateful to the staff for looking into options to find her a new roommate.

Of course, I have a roommate. Most everybody has private rooms. And I have to learn to live with sharing. And it's been very interesting. I've had all kinds of people. The first one I had was, she had Alzheimer's. I guess she wasn't ready to go in the other apartment [dementia care unit] yet. I never knew what I'd find when I opened the door. Sometimes she'd take the pictures off the wall and pile them all on the table. Sometimes she put her sweater in the refrigerator. It was a real experience, but she was a nice person. So, right now I'm contending with one that is pretty hard. They are going to move her when they find a place. We share the bathroom and she is not clean. And it's pretty hard. But it will change. I'm patient.

Once issues develop between roommates, many AL's, like the Chesapeake, will do what they can to accommodate a switch. Mr. Goddin, a resident of Arcadia Springs, was fortunate to have a Medicaid waiver for his spot in AL, though it meant he had a shared room. His roommate would keep open containers of cookies, peanut butter, and candy that attracted ants into their room and eventually into Mr. Goddin's bed.

Privacy and how it affects modesty appears to operate differently in AL. For example, there were situations where we would knock and then be called into the room by a resident who was either undressed or in the process of dressing, or using the toilet with the bathroom door open. In one case, one woman was naked from the waist down when the ethnographer entered the room to conduct a pre-scheduled interview. These individuals would see that we were not the aides, and yet continued to wave us into the room, apparently unconcerned by their state of dress. While this would cause the researchers some discomfort, the partially clothed resident did not seem fazed. Research on privacy in nursing homes has shown that privacy is not preserved when residents are seen as "objects" (Applegate and Morse, 1994). The converse seems to be in operation in these presumably private places where expected rules of modesty are not followed. Chapman and Carder (2003) note that privacy norms appear to be altered by advanced dementia, although our examples above do not involve people with advanced dementia. One explanation may be residents' dependency upon others for assistance with intimate personal needs. These needs, tended by a string of care aides entering their room, many of whom are strangers because of staff turnover, perhaps modify the usual rules of modesty. Therefore, it may be that what visitors to AL think of as a violation of privacy is not always perceived as such by residents (Chapman and Carder, 2003).

AL's vernacular, hidden personal spaces provide an intimate look at the proactive and often creative ways residents respond to their environment. A private room is not as private as one might expect. Because of this, residents may surreptitiously hide items from staff or learn to adjust their personal sense of modesty. Or like Mrs. Tice and Mrs. Merrill, they may become more tolerant and understanding, all of which can be effective courses of action that to an outsider may seem like inaction. These residents understand the necessary compromise, exchanging some level of privacy and self-determination for the security and comfort AL affords.

\section{Limits and Suggested Research Directions}

In the large studies we draw upon for this article, we did not consistently include the perspective of the authorities, such as the fire marshals, though some ethnographer's attended state-wide AL workgroup meetings and met with other professionals working in 
that arena. To get a more complete picture of the AL landscape, both its formalized and vernacular aspects, an effort should be made to include their perspectives.

The aims of the qualitative studies referenced in this article varied, but they all shared a focus on the interaction of people and place. Even though no consistent set of questions were asked pertaining to the concept of improvised or unplanned use of space, the usefulness of the concept is evident as we read the words of residents and ethnographers' fieldnotes. What we present hereiv is what emerged through conversations, observations, or interviews where the question prompting the topic was something like, "Where do people socialize here?" It is likely that, had we pursued the topic of spontaneous gathering places, for example, we would have discovered more instances, providing us with more stories, perhaps filling out some of the gaps or providing contrast to some of the conclusions we have drawn here.

Future research directions might include an exploration of the social and private vernacular spaces that care aides or administrative staff inhabit/create, in an effort to understand and uncover the ways they shape their work environment and vice versa. Though this kind of participant observation research is time-consuming, it yields a nuanced and deeper understanding than standard surveys. Viewing complex settings like AL as a vernacular landscape provides a new lens-a way to integrate social, cultural, political, and environmental aspects of these increasingly prevalent senior housing settings.

\section{In Summary}

The vernacular landscape of AL reveals what are often under-recognized expressions of power and control by AL residents. By looking more closely, listening more intently, and better understanding the unique cultural context of each AL, vernacular spaces are indeed being created all the time. These acts of agency are often not obvious at first glance.

Residents creatively adapt to their physical environment as a way to create sociability (pulling chairs out into a hallway) or avoid socializing by retreating to the refuge of one's individual room; some have adapted to the lack of privacy by adjusting one's own sense of modesty; many express acceptance and understanding of those who suffer from dementia and wander into their private space; some choose to hide forbidden items in their room and defy certain rules or expectations either openly or quietly.

The way space is used in AL has perhaps diverged from its original intentions. As a place formally designed to provide a more home-like environment, the people who live and work there have over time helped shape what AL has become, for better and for worse. In many places, dining rooms have become too small to accommodate the increased numbers of wheelchairs and walkers. Individual rooms have come to house two individuals as the desire to stay within AL may require sacrificing privacy. Designated social space and planned activities may fail to draw people together to socialize. To ensure safety, as well as avoid liability, nightly checks have become accepted as common practice in AL.

What conflict does exist over both planned and vernacular public and private space we propose is largely the result of living within an environment that is both someone's home as well as a place of business whose job it is to keep people safe. With that mandate come all the restrictions and regulations that naturally impinge upon the lives of the people who live there. This conflict is played out in the physical environment as, for example, fire codes clash with resident-created gathering places. It is in these vernacular spaces that residents

\footnotetext{
${ }^{i v}$ The situations we include in this paper are not an exhaustive list of vernacular spaces found in our data. For example, one setting's residents informally and routinely shared Sunday evening supper together around a small table in the shared kitchenette.
} 
create a "sense of being in place"-where individual rooms become inscribed and embodied and social spaces are spontaneously created despite the obstacles. These obstacles, though at times put there by the regulations governing $\mathrm{AL}$ or $\mathrm{AL}$ operators/managers, are not entirely to blame. Indeed, the administration at Murray Ridge celebrated the Forum and mourned when it died. But because of the power vested in these entities, the ways they shape and mold these living and work environments is perhaps more readily apparent.

The lesson learned from Jackson, with the help of ethnography, is that it is possible to locate within the formalized and dominant landscape of AL, "spaces of a humbler, less permanent, less conspicuous sort" (Jackson, 1984:xi). Created by residents, these "humbler" spaces that make up the vernacular landscape for the time people inhabit them, enliven and perhaps make more livable this place called Assisted Living.

\section{Acknowledgments}

The authors wish to thank the reviewers for their thoughtful critique, Kate deMedeiros and Jill Stein for their valuable feedback, Patrick Doyle for his research assistance, and ethnographers Paula Carder Leanne Clark, Ann Christine Frankowski, Lynn Keimig, Mary Nemec, Carolyn North, and Amanda Peeples for their keen insights in the field. In particular, we recognize the people within the AL settings who have shared generously of their time and experiences.

Research supported by National Institute on Aging grants: R01 AG19345 \& R01 AG028469, J. Kevin Eckert, P.I. and R01 AG022563, Leslie A. Morgan, P.I.

\section{WORKS CITED}

Agar M. Stories, background knowledge and themes: Problems in the analysis of life history narrative. American Ethnologist. 1980; 7(2):223-239.

Agich, GJ. Dependence and Autonomy in Old Age: An Ethical Framework for Long-Term Care. 2nd revised edition. Cambridge: Cambridge University Press; 2003.

Applegate M, Morse JM. Personal privacy and interactional patterns in a nursing home. Journal of Aging Studies. 1994; Vol. 8(4):413-434.

Ball MM, Perkins FJ, Whittington C, Hollingsworth SV, King BL, Combs. Independence in assisted living. Journal of Aging Studies. 2004; 18:467-483.

Calkins MP. Powell Lawton's Contributions to Long-Term Care Settings. Journal of Housing for the Elderly. 2003; Vol. 17(No. 1/2):67-84.

Carder PC. The social world of assisted living. Journal of Aging Studies. 2002; 16:1-18.

Carder PC, Hernandez Mauro. Consumer Discourse in Assisted Living. Journal of Gerontology. 2004; Vol. 59B(2):S58-S67.

Carder PC, Schumacher JG, Zimmerman S, Sloane PD. Medication Management: Integrating the Social and Medical Models. Assisted Living Consult. 2007:18-22.

Chapman NJ, Carder PC. Privacy Needs When Visiting a Person with Alzheimer's Disease: Family and Staff Expectations. Journal of Applied Gerontology. 2003; 22:506.

Cowdry, EV., editor. Problems of Ageing. Baltimore: Williams \& Wilkins Company; 1942.

Crabtree, BF.; Miller, WL. A template approach to text analysis: Developing and using codebooks. In: Crabtree, BF.; Miller, WL., editors. Doing qualitative research. Thousand Oaks, CA: US, Sage Publications, Inc; 1992. p. 93-109.

Cumming, E.; Henry, WE.; Damianopoulos. A formal statement of disengagement theory. In: Cumming, E.; Henry, WE., editors. Growing old: The process of disengagement. New York: Basic Books; 1961.

Eckert, JK.; Carder, PC.; Morgan, LA.; Frankowski, AC.; Roth, EG. Inside Assisted Living: A Search for Home. Baltimore: Johns Hopkins Press; 2009.

Foucault, M. Survelleir et punir. Naissance de la prison. Paris: Gallimard; 1975. (English trans.

Discipline and Punish, London: Penguin, 1979.) 
Gamliel T. The lobby as an arena in the confrontation between acceptance and denial of old age. Journal of Aging Studies. 2000; Vol. 14(Issue 3):251-271.

Goffman, E. The presentation of self in everyday life. Garden City, NY: Doubleday; 1959.

Golant, SM. The future of assisted living residences. In: Golant, SM.; Hyde, J.; Golant, SM.; Hyde, J., editors. The Assisted Living Residence: A Vision for the Future. Baltimore: Johns Hopkins Press; 2008. p. 3-45.

Gubrium, JF.; Holstein, JA., editors. Ways of aging. Oxford: Blackwell;

Hauge S, Heggen K. The nursing home as a home: a field study of residents' daily life in the common living rooms. Journal of Clinical Nursing. 2007; Vol. 17(4) 460-46.

Jackson, JB. Discovering the Vernacular Landscape. London and New Haven: Yale University Press; 1984.

Kahana, E. A congruence model of person-environment interaction. In: Lawton, MP.; Windley, PG.; Byerts, TO., editors. Aging and the environment: Directions and perspectives. New York: Garland STPM Press; 1980.

Kane R, Kane R. What older people want from long-term care, and how they can get it. Health Affairs. 2001; 20:114-127. [PubMed: 11816651]

Kane R, Kling K, Bershadsky B, Kane R, Giles K, Degenholtz H. Quality of life measures for nursing home residents. Journal of Gerontology: Medical Sciences. 2003; 58A(3):240-248.

Kossuth, PM.; Bengtson, V. Sociological Theories of Aging: Current Perspectives and Future Directions. In: Birren, JE.; Bengtson, VL., editors. Emergent Theories of Aging. New York: Springer Publishing Company; 1988.

Lawton, MP.; Nahemow, L. Ecology and the aging. In: Eisdorfer, C.; Lawton, PM., editors. The psychology of adult development and aging. Washington: American Psychological Association; 1973. p. 619-675.

Lawton, MP. Environment and Aging. Monterrey, CA: Brooks/Cole; 1980.

Lawton, MP. Environment and Aging: Theory Revisited. In: Scheidt, RJ.; Windley, PG., editors. Environment and Aging Theory: A Focus on Housing. Westport, CT: Greenwood Press; 1998.

Lippard, L. Lure of the Local: Senses of Place in a Multicentered Society. New York: The New Press; 1998.

Low, Setha; Lawrence-Zuniga, Denise. The Anthropology of Space and Place: Locating Culture. Oxford: Blackwell Publishing; 2003.

Low, Setha; Smith, Neil, editors. The Politics of Public Space. New York: Routledge; 2006.

McColgan G. A Place to Sit: Resistance Strategies Used to Create Privacy and Home by People with Dementia. Journal of Contemporary Ethnography. 2005; 34(4):410-433.

Miles, MB.; Huberman, AM. Qualitative data analysis: An expanded sourcebook. Thousand Oaks, CA: Sage Publications; 1994.

Mollica, RL. AHRQ Publication No. 06-M051-EF. Rockville, MD: Agency for Healthcare Research and Quality; 2006. Residential Care and Assisted Living: State Oversight Practices and State Information Available to Consumers.

Moore K. Dissonance in the Dining Room: A Study of Social Interaction in a Special Care Unit. Qualitative Health Research. 1999; 9(1):133-155. [PubMed: 10558356]

Morgan LA. Balancing Safety and Privacy: The Case of Room Locks in Assisted Living. Journal of Housing for the Elderly. 2009; 23:185-203.

Morgan, LA.; Frankowski, AC.; Roth, EG.; Keimig, L.; Zimmerman, S.; Eckert, JK. The Quality Balance in Assisted Living: Translating Research into Practice. New York: Springer; (forthcoming).

Muhr, T. Atlas.ti version 5.2.21. Berlin: Scientific Software Development; 2008.

Parmalee, P.; Lawton, MP. The design of special environments for the aged. In: Birren, J.; Schaie, W., editors. Handbook of the psychology of aging. San Diego, CA: Academic Press; 1990. p. 464-488.

Rowles, GD. Prisoner of Spaces? Exploring the Geographical Experiences of Older People. Boulder: Westview Press; 1978. 
Rowles, GD.; Oswald, F.; Hunter, EG. Interior living environments in old age. In: Wahl, H-W.; Scheidt, RJ.; Windley, PG., editors. Aging in context: Socio-physical environments. New York: Springer; 2005. p. 167-194.

Rubinstein RL. Personal Identity and Environmental Meaning in Later Life. Journal of Aging Studies. 1990; 1:225-238.

Rubinstein, RL.; de Medeiros, K. Ecology and the aging self. In: Wahl, H-W.; Scheidt, RJ.; Windley, PG., editors. Aging in context: Socio-physical environments. New York: Springer; 2003. p. 59-84.

Stafford, PB. Elderburbia: Aging with a Sense of Place in America. Santa Barbara: Praeger; 2009.

Tuan, YF. Introduction. In: Tuan, Yi-Fu, editor. Space and Place: the Perspective of Experience. Minneapolis: University of Minnesota Press; 1977. p. 6

Rahman AN, Schnelle JF. The nursing home culture-change movement: recent past, present, and future directions for research. Gerontologist. 2008; 48(2):142-148. [PubMed: 18483426]

Wahl HW, Weisman GD. Environmental Gerontology at the Beginning of the New Millennium: Reflects on Its Historical, Empirical, and Theoretical Development. The Gerontologist. 2003; 43(5):616-627. [PubMed: 14570958]

Weiner, AS.; Ronch, J., editors. Culture Change in Long-Term Care. Binghamton, NY: Haworth Social Work Practice Press; 2003.

Werner, O.; Schoepfle, GM., et al. Systematic fieldwork. Newbury Park, CA: Sage Publications; 1987.

Wilcocks, D.; Peace, S.; Kellaher, L. Private lives in public pladces. London: Tavistock; 1987.

Zimmerman, S.; Sloane, PD.; Eckert, JK., editors. Assisted living: needs, practices, and policies in residential care for the elderly. Baltimore: Johns Hopkins University Press; 2001.

J Aging Stud. Author manuscript; available in PMC 2012 August 1. 